\title{
Processing irrelevant location information: Practice and transfer effects in choice-reaction tasks
}

\author{
ROBERT W. PROCTOR \\ Purdue University, West Lafayette, Indiana \\ and \\ CHEN-HUI LU \\ Providence University, Taiwan, Republic of China
}

\begin{abstract}
Left or right keypresses to a relevant stimulus dimension are faster when the stimulus location, although irrelevant, corresponds with that of the response than when it does not. This phenomenon, called the Simon effect, persisted across 1,800 trials of practice, although its magnitude was reduced. Practice with the relevant stimulus dimension presented at a centered location had little influence on the magnitude of the Simon effect when irrelevant location was varied subsequently, and practice with location irrelevant prior to performing with location relevant slowed responses. After practice responding to stimulus location with an incompatible spatial mapping, the Simon effect was reversed (i.e., responses were slower when stimulus location corresponded with response location) when location was made irrelevant. When the response keys were labeled according to the relevant stimulus dimension (the Hedge and Marsh [1975] task variation), this reversal from practice with a spatially incompatible mapping was found for both the congruent and the incongruent relevant stimulus-response mappings. Thus, task-defined associations between stimulus location and response location affect performance when location is changed from relevant to irrelevant, apparently through producing automatic activation of the previously associated response.
\end{abstract}

The way in which the processing of information changes with practice is of central interest in the study of human performance (see Proctor \& Dutta, 1995, for a review). This issue has been investigated in a variety of tasks, including but not limited to visual search and memory search (e.g., Shiffrin \& Schneider, 1977), lexical decision (e.g., Logan, 1990), problem solving (e.g., Carlson, Khoo, Yaure, \& Schneider, 1990), and sequence learning (e.g., Cohen, Ivry, \& Keele, 1990). In different tasks, practice has been shown to promote (1) perceptual unitization of features and forms (see, e.g., Pellegrino, Doane, Fischer, \& Alderton, 1991), (2) strengthening of stimulus-tointerpretation associations (e.g., associations of stimuli to word and nonword categories in lexical decision tasks; Logan, 1990), (3) development of time-sharing skill (see, e.g., Gopher, Brickner, \& Navon, 1982), (4) incidental learning of sequential structure (see, e.g., Cohen et al., 1990), and (5) speedup of component problem-solving processes (see, e.g., Carlson et al., 1990), among other things. In general, the benefits of practice have been found to be relatively specific to the items practiced and the conditions under which they were practiced (see, e.g., Healy \& Bourne, 1995; Logan, 1990) but not to the physical responses that were made (see, e.g., Cohen et al., 1990;

We thank Peter Dixon, Gordon Logan, and John Wixted for helpful comments on an earlier version of this paper. Correspondence concerning this article should be sent to R. W. Proctor, Department of Psychological Sciences, Purdue University, West Lafayette, IN 47907-1364 (e-mail: proctor@psych.purdue.edu).
Logan, 1990; Shiffrin \& Schneider, 1977). Although there are many characterizations of the changes that occur with practice and how and why they occur, most accounts describe a shift from an effortful, attentional mode of performance to one that is automatic and relatively effortless (e.g., Fitts \& Posner, 1967; Logan, 1988; Shiffrin \& Schneider, 1977).

One category of tasks in which practice effects and issues of automaticity and attention have been examined is choice-reaction tasks in which subjects respond as quickly as possible to a stimulus with an assigned keypress response. In such tasks, responses become faster and more accurate as subjects become practiced. In fact, according to Rabbitt (1989), the amount of practice is the single most important variable affecting the speed and accuracy of choice reactions. Given that practice exerts a strong effect on choice reactions, the question of what processes are affected arises.

Most information-processing models of human performance distinguish between a minimum of three processes: stimulus identification (or stimulus encoding), response selection (or stimulus-response [S-R] translation), and response preparation and execution (or motor programming). In many choice-reaction tasks, the primary influence of practice is on the intermediate stage, that of response selection or S-R translation (see, e.g., Teichner \& Krebs, 1974; Welford. 1976). Teichner and Krebs analyzed results from 59 choice-reaction studies that used simple visual stimuli presented in central vision without any distractor items present. They concluded that "the most im- 
portant effect of practice is on the stimulus-response translation stage" (p. 95).

More recently, Pashler and Baylis (1991) reached a similar conclusion from five experiments they conducted in which subjects practiced making keypress responses to symbolic stimuli with the index, middle, and ring fingers of the right hand. In their Experiment 1, two letters were assigned to one finger, two digits to another, and two nonalphanumeric characters to a third finger. Reaction times (RTs) decreased by approximately $150 \mathrm{msec}$ from the first to the last of 15 blocks of 50 trials each. After the 15 th block, two additional stimuli from each category were assigned to the respective responses, and 5 additional trial blocks were conducted. In Pashler and Baylis's words, "The new items in the trained categories enjoyed virtually the entire benefit obtained by the old (previously trained) items in these categories" (p. 25), suggesting that the benefit of practice was not on encoding of the specific stimuli. Pashler and Baylis's Experiment 5 showed little decrement in performance when, in addition to introducing new items from the categories after the 15 trial blocks, the hand used to make the keypresses was changed from right to left (or vice versa). The results showed essentially perfect transfer from one hand to the other, consistent with the above-mentioned fact that the benefits of practice generalize across physical responses. This transfer implies that the learning that occurred during practice did not involve the generation of specific motor responses. In summarizing the implications of these and their other experiments, Pashler and Baylis concluded, "Together, these results indicate that practice in speeded choice tasks affects primarily the response selection stage, rather than perceptual processing or motor responses" (p. 20).

\section{Stimulus-Response Compatibility and the Simon Effect}

Another major determinant of performance in choicereaction tasks, which is also presumed to exert its influence on response selection processes, is $\mathrm{S}-\mathrm{R}$ compatibility. Element-level S-R compatibility effects are differences in RT and accuracy for different mappings of the stimuli to responses (see Hommel \& Prinz, 1997, and Proctor \& Reeve, 1990, for reviews). For two-choice tasks, in which left and right stimulus locations are mapped to left and right keypresses, RTs are typically $60-80 \mathrm{msec}$ faster if the left stimulus is assigned to the left response and the right stimulus to the right response than if the mapping is reversed (see, e.g., Dutta \& Proctor, 1992; Wang \& Proctor, 1996).

Most accounts of spatial compatibility effects attribute them to response selection processes that activate spatial response codes (e.g., Umiltà \& Nicoletti, 1990). Spatial coding is implicated by such findings as that the compatibility effect still occurs when the arms are crossed, so that the left key is pressed with the right hand and the right key with the left hand (see, e.g., Brebner, Shephard, \& Cairney, 1972; Proctor \& Dutta, 1993), and when the two response locations or two stimulus locations are located in the same hemispace (see, e.g., Nicoletti, Anzola, Luppino, Rizzolatti, \& Umiltà, 1982; Proctor, Van Zandt, Lu, \& Weeks, 1993). There seems to be unanimous agreement that at least part of the spatial compatibility effects can be attributed to an explicit S-R translation based on the task-defined mapping provided by the instructions (see Figure 1, top route). Translation of the stimulus into its assigned response is presumed to occur faster when an identity rule (i.e., respond at the corresponding response location), rather than an opposite rule or a search of a list of S-R relations, can be used (see, e.g., Rosenbloom \& Newell, 1987). Several recent accounts also propose a second contributor to S-R compatibility effects (see Figure 1, bottom route)-automatic activation of the spatial response code corresponding to that of the spatial stimulus code (see, e.g., Barber \& O'Leary, 1997; Kornblum, Hasbroucq, \& Osman, 1990; Ridderinkhof, 1997). This activation is presumed to be beneficial when it is correct (i.e., for a compatible mapping) and harmful when it is incorrect (i.e., for an incompatible mapping).

Stimulus location also affects performance when location is defined as being irrelevant to the task. For example, if a right response is to be made to a red stimulus and a left response to a green stimulus, the RT to the red stimulus is faster when the stimulus occurs on the right side, and the RT to the green stimulus is faster when it occurs on the left side. This effect of irrelevant location is called the Simon effect when the relevant stimulus dimension does not involve spatial information, as in the above example, and is sometimes called the spatial Stroop effect when the relevant stimulus dimension also involves spatial information (e.g., the words left and right; see Lu \& Proctor, 1995, and Simon, 1990, for reviews). Although a few authors have suggested that the Simon effect has its locus in stimulus identification processes (Hasbroucq \& Guiard, 1991; Stoffels, van der Molen, \& Keuss, 1989), the preponderance of evidence points to the conclusion that the effect is a variant of S-R compatibility that is due primarily to response selection processes (see, e.g., De Jong, Liang, \& Lauber, 1994; Hommel, 1995; Proctor \& Wang, 1997; Umiltà \& Nicoletti, 1990).

As with S-R compatibility proper, the Simon effect is thought to reflect spatial coding. In this case, the irrelevant stimulus location code is presumed to produce activation of the corresponding response location code through long-term associative pathways (i.e., by automatic activation, the bottom route in Figure 1). This activation competes with that produced by the relevant stimulus information through short-term, task-defined pathways (i.e., by explicit S-R translation, the top route in Figure 1) when the two sources of information are in conflict and cooperates when they are in agreement (Barber \& O'Leary, 1997; Zorzi \& Umiltà, 1995). The activation produced by the irrelevant stimulus location code tends to decrease across time, resulting in a smaller Simon effect when the response to the relevant stimulus dimension is slowed (De Jong et al., 1994; Hommel, 1993b; Lu 


\section{RESPONSE SELECTION}

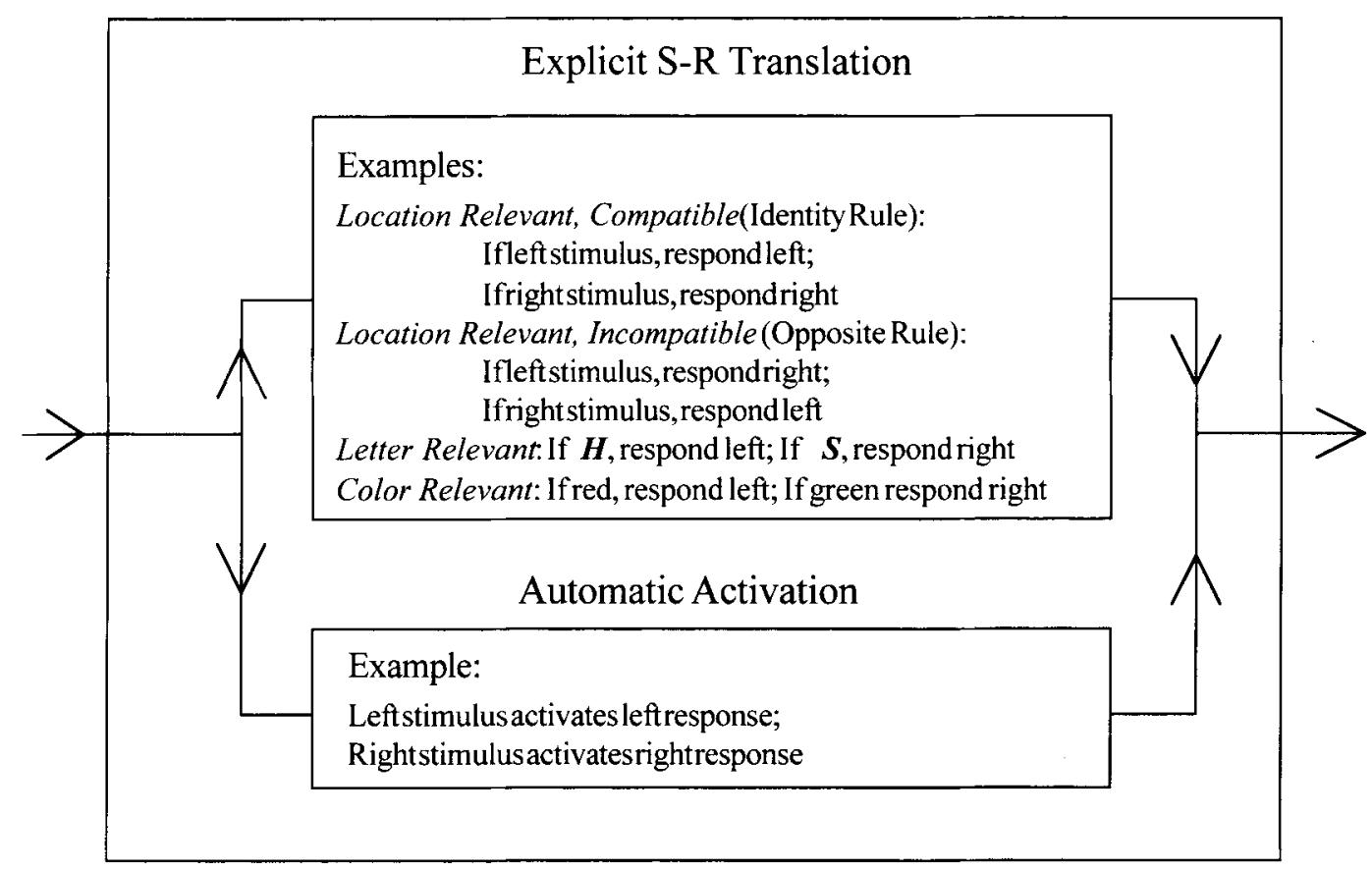

Figure 1. Generic dual-route response selection model. In all choice-reaction tasks, selection based on the task instructions is presumed to occur via an explicit stimulus-response (S-R) translation route. Additionally, when the alternative responses are left and right keypresses, as in the present study, a stimulus presented in a left or a right location is presumed to activate the corresponding response code via an automatic activation route. It is widely accepted that automatic activation of the corresponding response occurs when stimulus location is defined as irrelevant and is the basis of the Simon effect. There is less agreement regarding the contribution of the automatic activation route when stimulus location is defined as relevant.

\& Proctor, 1994; Roswarski \& Proctor, 1996). Many aspects of the results obtained for tasks in which irrelevant information affects performance, including the Simon effect and the Stroop effect, can be accommodated by the view that the irrelevant information produces transient activation of the corresponding response code. The magnitude of the effect of this irrelevant information is a function of the strength of its activation relative to that produced by the relevant information and of the degree to which the two sources of activation overlap in time (see, e.g., Lu, 1997).

Hedge and Marsh (1975) introduced an interesting variant of the Simon task in which the response keys are labeled according to the relevant stimulus dimension, and the task instructions are given entirely in terms of this dimension. For example, with red and green stimuli presented to the left or right, the left and right keys are labeled red and green. The instructions can be to respond with either a congruent color mapping (i.e., with the red key to a red stimulus and the green key to a green stimulus) or an incongruent color mapping (i.e., with the green key to a red stimulus and the red key to a green stimulus). Although the congruent mapping yields a standard Simon effect, the incongruent mapping yields a reversed Simon effect in which the responses are slower and less accurate when the stimulus location corresponds with that of the response. Moreover, whereas the Simon effect in both the original Simon task and the congruent version of the Hedge and Marsh task decreases in magnitude as responding is delayed, the reversed Simon effect increases in magnitude (De Jong et al., 1994; Lu $\&$ Proctor, 1994). There is more dispute about the cause of the reversed Simon effect than about the cause of the basic Simon effect, but the most widely accepted view seems to be that of logical recoding (De Jong et al., 1994; Hedge \& Marsh, 1975; Lu \& Proctor, 1994). According to this view, the opposite rule (i.e., respond with the key of opposite value to that of the stimulus), which is appropriate for the incompatibly mapped, relevant color dimension, is inappropriately applied to the irrelevant location dimension when translating the relevant stimulus dimension into a spatial response code.

\section{Influence of Practice on S-R Compatibility and Simon Effects}

Given that the effects of spatial compatibility (for either relevant or irrelevant location information) and practice in choice-reaction tasks both seem to be based pri- 
marily in response selection processes, a natural question is how the compatibility effects change as a function of practice. For spatial S-R compatibility proper, there are numerous demonstrations that the effects are robust with respect to practice (see, e.g., Fitts \& Seeger, 1953). For the two-choice task, Dutta and Proctor (1992) had subjects practice for eight sessions of 280 trials each with either a compatible or an incompatible mapping. The magnitude of the compatibility effect decreased from $72 \mathrm{msec}$ in the first session to an asymptotic value of $42 \mathrm{msec}$ for the last four sessions. Even the provision of RT feedback after each block of 20 trials and the implementation of response deadlines did not enable the advantage for the spatially compatible mapping to be eliminated with practice (Dutta \& Proctor, 1993). The persistence of spatial compatibility effects implies that response selection continues to be mediated by spatial response codes, rather than being based on direct associations between stimulus locations and their assigned physical responses, even after extensive practice.

We are aware of only two studies that have examined the Simon effect as a function of practice. Simon, Craft, and Webster (1973) had persons press a left or a right key in response to a high- or low-pitched tone presented in the left or the right ear. A total of 216 trials was performed on each of 5 days. The magnitude of the Simon effect decreased from approximately $60 \mathrm{msec}$ in the $1 \mathrm{st}$ session to $35 \mathrm{msec}$ in the 5 th session, but the effect was not eliminated. Hommel (described in Prinz, Aschersleben, Hommel, \& Vogt, 1995) tested a single subject for 30 sessions of 210 trials each, using a similar method. The Simon effect was present for this subject in all sessions, averaging more than $50 \mathrm{msec}$ in the first 3 sessions and approximately $20 \mathrm{msec}$ in the last 20 sessions. Thus, the data on the Simon effect are in agreement with those on S-R compatibility proper in showing that the effect decreases with practice but persists at a reduced magnitude. In other words, the irrelevant stimulus location information continues to affect performance after substantial practice, although to a reduced extent.

\section{Use of Transfer Designs}

Transfer designs have a long history of use for evaluating the nature of the changes in information processing that occur as a function of practice with a task (Proctor $\&$ Dutta, 1995). Typically, subjects are transferred after practice to one or more conditions that share some features of the practice conditions but differ in other respects. As is illustrated by the Pashler and Baylis (1991) study described early in the introduction, the nature of the learning that has occurred can be specified by comparing the situations for which transfer is evident with those for which it is not. In the two-choice spatial compatibility task, Proctor and Dutta (1993) had subjects practice for three sessions of 300 trials each, using a crossed or uncrossed hand placement with a spatially compatible or incompatible mapping. When transferred to a new placement/mapping condition in a fourth session, positive transfer was found when the spatial mapping (compatible or incompatible) remained the same but not when it was changed. Proctor and Dutta (1993) also found a significant cost of switching every 40 trials between crossed and uncrossed hand placements if the spatial mapping was changed so that each finger always responded to the same stimulus, but not if the spatial mapping remained constant. Thus, the transfer studies with two-choice tasks suggest that practice strengthens the task-defined associations between stimulus locations and response locations, rather than those between stimulus locations and fingers. Note that this conclusion is in agreement with Logan's (1990) conclusion that practice at a lexical decision task strengthens associations between stimuli and their assigned categories (word, nonword), rather than between stimuli and their assigned physical responses.

Transfer designs would seem to be useful tools for investigating the manner in which irrelevant stimulus location information influences performance, as in the Simon task, and how the processing of this location information changes with practice. For one, practice with the relevant stimulus information in the absence of the irrelevant location information, followed by transfer to the Simon task, can be used to assess the extent to which practice effects in the Simon task require the varying of location. For another, practice with the Simon task, followed by transfer to conditions in which stimulus location is relevant, and vice versa, can illuminate the relation between unintentional and intentional activation of response location codes in response to stimulus location. To our knowledge, transfer designs have not been used in this manner to examine the Simon effect. However, they have been used with some success to investigate the processing of irrelevant information in the closely related Stroop color-naming task and its variants.

Two studies that are pertinent to our present concerns are those of Reisberg, Baron, and Kemler (1980) and Clawson, King, Healy, and Ericsson (1995). Reisberg et al. examined practice and transfer effects for a task in which subjects had to name, as quickly and accurately as possible, the number of symbols (one, two, three, or four) in each row on a page. For the Stroop-type pages, half of the rows were composed of instances of one digit (e.g., 2) and half of another digit (e.g., 4). The Stroop effect (i.e., slower and less accurate naming for these lists than for ones composed from nonalphanumeric symbols) decreased but did not disappear across three practice blocks of 10 pages each. This benefit of practice transferred to pages composed from words of the same meaning (two and four), but not to ones composed from similar sounding words ( $t o$ and $f o r$ ) or different digits ( $I$ and 3 ). The transfer results suggest that subjects learned to inhibit the cognitive codes corresponding to the meanings of the specific irrelevant digits with which they practiced.

Clawson et al. (1995) obtained comparable results for the Stroop color-naming task (i.e., naming the colors of incongruous color words). Practice at the Stroop task, but not practice at naming color patches, reduced the 
Stroop effect magnitude from pretest to posttest. This outcome suggests that the benefit of practice at the Stroop task is on suppression of the irrelevant color-word information. The practice benefit was not specific to the word form used during practice (lowercase letters) because the decrease in RT from pretest to posttest was equally evident for Stroop stimuli in which each letter was uppercase or was flanked by asterisks. However, the improvement from practice at the Stroop color-naming task was better for stimuli composed from the trained color set than for stimuli composed from a different set of colors. Thus, both the Reisberg et al. (1980) and the Clawson et al. studies imply that the reduction of effects of irrelevant information with practice occurs through suppression of the cognitive codes activated by that information.

\section{Purpose}

The purpose of the present study was to investigate changes in the effect of irrelevant location information on performance in the Simon task as a function of practice at that task and of prior performance of tasks with different properties. The two previous studies that have examined practice effects in the Simon task-those of Simon et al. (1973) and Hommel (in Prinz et al., 1995) used auditory stimuli. In the present study, we used visual stimuli, consistent with most recent investigations of the Simon effect (see Lu \& Proctor, 1995). The Simon effect obtained with visual stimuli is typically considerably smaller than that obtained with auditory stimuli, often being in the range of $25 \mathrm{msec}$ or less (see, e.g., De Jong et al., 1994; Proctor \& Lu, 1994). Because the magnitude of the auditory Simon effect is more than twice that of the visual Simon effect, factors may contribute, at least in part, to the former that do not contribute to the latter. Consequently, evidence needs to be obtained regarding whether the visual Simon effect decreases with practice but persists at a reduced magnitude, as does the auditory Simon effect.

Experiment 1 served this purpose, both examining the influence of practice on the visual Simon effect and evaluating whether practice with the relevant stimulus dimension alone is sufficient to produce a reduction in the Simon effect. In Experiment 2, some subjects practiced the Simon task and then were tested with relevant stimulus location information, using either a spatially compatible or a spatially incompatible $\mathrm{S}-\mathrm{R}$ mapping. The intent was to evaluate whether the suppression of irrelevant location information would have persisting effects when location subsequently became relevant. Other subjects in Experiment 2 performed the spatial choice task with a compatible or incompatible mapping prior to the Simon task, with the goal of determining whether the taskdefined spatial mapping would alter the effect of stimulus location when it was subsequently made irrelevant to the task. Transfer from an incompatible spatial mapping to the Simon task was also examined in Experiment 3, with the major difference from Experiment 2 being that conditions were included for which the stimulus set used in the trans- fer session was different from the one used during practice. This allowed determination of whether the transfer effects from relevant location mapping are linked to the specific stimuli used in practice. Finally, in Experiment 4, we examined whether the transfer effects from prior practice with an incompatible spatial mapping add to or interact with the reversal of the Simon effect that occurs with the incongruent mapping of relevant $\mathrm{S}-\mathrm{R}$ dimensions in the Hedge and Marsh (1975) task.

\section{EXPERIMENT 1}

In Experiment 1, one group of subjects performed the Simon task for over 1,800 trials spread over three sessions of practice. The relevant stimulus dimension was letter identity ( $\mathrm{S}$ or $\mathrm{H})$, and stimulus location (left or right) was irrelevant to the response. A second group of subjects received the same amount of practice with the letters $\mathrm{S}$ and $\mathrm{H}$ as stimuli, but in a constant, centered location. We shall call this task the centered task. For the centered task, the explicit S-R translation route illustrated in Figure 1 contributes to performance, as in the Simon task, but the automatic activation route does not. In a fourth session, the tasks performed by the two groups were switched.

Experiment 1 provides information pertinent to several issues. First, practice with the Simon task enables determination of whether the Simon effect for visual stimuli reduces in magnitude but does not disappear, as is the case for auditory stimuli. Such a reduction would indicate a lessened effect of the irrelevant location information on performance. Second, practice with the centered task allows an amount of experience with the task-defined mappings of the relevant stimulus identities and their assigned responses that is comparable with practice with the Simon task, but not in the context of the irrelevant location information. The magnitude of the Simon effect in the subsequent transfer session should be reduced if practice with the relevant S-R mappings is the critical factor, but not if location must also vary for the practice to be effective. Third, the performance of subjects who are switched from the Simon task to the centered task in the transfer session can be compared with that of subjects who practiced the centered task. If the irrelevant location variable does not affect learning of the relevant S-R mappings, the transfer subjects' performance should be similar to the performance in Session 3 of the subjects who practiced the centered task.

\section{Method}

Subjects. Sixty students enrolled in introductory psychology classes at Purdue University participated to fulfill a course requirement. Each subject was tested in four sessions. Thirty received the Simon task in the first three sessions and the centered task in Session 4 , and 30 received the centered task in the first three sessions and the Simon task in the fourth session.

Apparatus, Stimuli, and Procedure. The stimuli were presented on the display screen of an IBM-compatible personal computer. Responses were made by pressing either the $z$ or the / key on 
the bottom row of the keyboard with the left or the right index finger, respectively. The experiment was conducted using the Micro Experimental Laboratory (MEL, Version 1.0) software system (Schneider, 1988) to control all timing and displays.

The stimuli were the uppercase letters $\mathrm{S}$ and $\mathrm{H}$. Each letter was approximately $0.5 \mathrm{~cm}$ in height and $0.35 \mathrm{~cm}$ in width and, at a viewing distance of approximately $55 \mathrm{~cm}$, subtended a visual angle of $0.52^{\circ} \times 0.37^{\circ}$. For the centered task, the stimulus was presented in the center of the screen. For the Simon task, the stimulus was presented in a left or right location for which the center-to-center separation was $2.5 \mathrm{~cm}$, or $2.6^{\circ}$.

Each of the four sessions began with a block of 8 practice trials. This was followed by two blocks of 4 practice and 304 test trials each. The subject initiated the block by pressing the spacebar with her or his thumbs, and the first stimulus was immediately presented. The stimulus remained on the screen until a response was made, and, $1 \mathrm{sec}$ later, the next stimulus was presented. If the response was incorrect, a low-pitched tone of $500 \mathrm{~Hz}$ sounded as feedback for $500 \mathrm{msec}$ prior to the $1-\mathrm{sec}$ intertrial interval.

There were three sessions of practice with the stimulus being either centered or presented in the left or the right location. In the fourth session, the subjects were transferred to the opposing condition (i.e., Simon or centered). Assignment of the letters $\mathrm{S}$ and $\mathrm{H}$ to the left and right responses was counterbalanced across subjects, with the same assignment being used by a given subject for all four sessions.

\section{Results}

Trials for which the RT was less than $200 \mathrm{msec}$ or more than $2,000 \mathrm{msec}(<1 \%$ of the responses) were excluded from the analyses in this experiment and in the others. The mean RT and error proportion (EP) as a function of group, session, and spatial correspondence are shown in Table 1.

Practice. For the subjects who practiced the Simon task, the RT data showed a main effect of spatial correspondence $\left[F(1,29)=97.2, M S_{\mathrm{e}}=132, p<.001\right]$. Responses were $17 \mathrm{msec}$ faster when the stimulus location

Table 1

Mean Reaction Time in Milliseconds and Error Proportion (EP) in Experiment 1 as a Function of Spatial Correspondence, Session, and Task Order (Simon $\rightarrow$ Centered or Centered $\rightarrow$ Simon)

\begin{tabular}{|c|c|c|c|c|c|c|c|c|}
\hline \multirow[b]{3}{*}{ Correspondence } & \multicolumn{6}{|c|}{ Practice Sessions } & \multirow{2}{*}{\multicolumn{2}{|c|}{$\frac{\text { Transfer Session }}{4}$}} \\
\hline & \multicolumn{2}{|c|}{1} & \multicolumn{2}{|c|}{2} & \multicolumn{2}{|c|}{3} & & \\
\hline & $M$ & $\overline{\mathrm{EP}}$ & $M$ & $\overline{\mathrm{EP}}$ & $M$ & $\overline{\mathrm{EP}}$ & $M$ & $\mathrm{EP}$ \\
\hline
\end{tabular}

$\begin{array}{lllllll}\text { Corresponding } & 459 & .02 & 462 & .01 & 462 & .01\end{array}$ $\begin{array}{lllllll}\text { Noncorresponding } & 481 & .03 & 476 & .02 & 476 & .02\end{array}$ Centered

$$
\text { Centered } \rightarrow \text { Simon }
$$

Corresponding

Noncorresponding

Centered

484

Note-The Simon $\rightarrow$ Centered group received the Simon task in Sessions $1-3$ and the centered task in Session 4; the Centered $\rightarrow$ Simon group received the centered task in Sessions $1-3$ and the Simon task in Session 4. The apparently identical mean RTs and EPs for Sessions 2 and 3 of the Simon $\rightarrow$ Centered group are not identical if extended one place further. corresponded with the response location $(M=461 \mathrm{msec})$ than when it did not $(M=478 \mathrm{msec})$. There was no main effect of session $\left[F(2,58)<1.0, M S_{\mathrm{e}}=1,710\right]$, but session interacted with spatial correspondence $[F(2,58)=5.55$, $\left.M S_{\mathrm{e}}=53, p<.01\right]$. The difference between corresponding and noncorresponding $S-R$ locations was 22,14 , and $14 \mathrm{msec}$ in Sessions 1, 2, and 3, respectively. The error data tended to show a main effect of session $[F(2,58)=$ $\left.3.01, M S_{\mathrm{e}}=0.00865, p=.057\right]$ and did show a significant main effect of correspondence $\left[F(1,29)=26.4, M S_{\mathrm{e}}=\right.$ $0.00716, p<.001]$. The proportion of errors was larger in Session $1(\mathrm{EP}=.025)$ than in Sessions $2(\mathrm{EP}=.015)$ and $3(\mathrm{EP}=.015)$ and less when stimulus and response locations corresponded $(E P=.013)$ than when they did not $(\mathrm{EP}=.023)$. The session $\times$ correspondence interaction for errors was not significant $(F<1.0)$.

For the subjects who practiced the centered task, the only independent variable of interest was session. Although both RT and EP tended to decrease across sessions (see Table 1), session did not have a significant effect for either measure $\left[F \mathrm{~s}(2,58)=1.75\right.$ and $1.77, M S_{\mathrm{e}} \mathrm{s}=623$ and $0.00009, p s<.20$, respectively]. However, omission of 1 subject whose responses averaged $87 \mathrm{msec}$ slower in Sessions 2 and 3 than in Session 1, without corresponding increases in accuracy, doubled the $F$ ratio for the RT measure $\left[F(2,56)=3.50, M S_{\mathrm{e}}=516, p=.044 ; M \mathrm{~s}=436\right.$, 422 , and $423 \mathrm{msec}$ for Sessions 1-3]. It seems reasonable to conclude, on the basis of these analyses, that performance of the centered task improved with practice, although the practice effect was not particularly strong.

Transfer. The performance of the subjects in Session 4 who switched to the Simon task from the centered task was more like that in Session 1 than like that in Session 3 for the subjects who practiced the Simon task. Responses were both faster $(21 \mathrm{msec})$ and more accurate $(.02)$ when stimulus location and response location corresponded than when they did not $\left[F \mathrm{~s}(1,29)=68.9\right.$ and $18.4, M S_{\mathrm{e}} \mathrm{s}=$ 97.8 and $0.00022, p s<.001$, respectively]. Moreover, comparisons with Session 1 of the group who practiced the Simon task for three sessions showed neither main effects of session nor interactions with correspondence for RTs or errors $(F \mathbf{S}<1.0)$. In contrast, comparisons with Session 3 (Simon effect of $14 \mathrm{msec}$ ) indicated that the correspondence effect for RTs was larger for the subjects who transferred to the Simon task in Session 4 [Simon effect of $\left.21 \mathrm{msec} ; F(1,58)=4.14, M S_{\mathrm{e}}=91.1, p<.05\right]$.

For the subjects who switched from the Simon task to the centered task, mean RT in the transfer session was similar to that in Session 1 for the subjects who practiced with the centered task. However, comparisons showed no statistically significant difference in RT between the transfer session and either Session 1 or Session $3\left(F_{\mathbf{s}}<1.0\right)$. Moreover, EP tended to be smaller for the centered task in the transfer session than in Session $1[F(1,58)=3.11$, $\left.M S_{\mathrm{e}}=0.0004, p=.083\right]$, but not in Session $3(F<1.0)$. The EP and RT data together, although far from un- 
equivocal, suggest that practice at responding to letter identity with location varying may yield a small benefit in performance when the letters subsequently are displayed at a constant, centered location.

\section{Discussion}

A Simon effect of $22 \mathrm{msec}$ was evident in the first session for subjects who practiced the Simon task. This effect decreased significantly in magnitude to $14 \mathrm{msec}$ in Sessions 2 and 3. Thus, the visual Simon effect was reduced but not eliminated with practice, as occurs for the auditory Simon effect (Hommel, in Prinz et al., 1995; Simon et al., 1973).

For the subjects who practiced the centered task, the Simon effect in the transfer session was $21 \mathrm{msec}$, a value that was similar to the first session for the subjects who practiced the Simon task. Thus, practice with the nonspatial relevant stimulus dimension alone was not sufficient to produce a reduction in the Simon effect similar to that which occurred when the Simon task itself was practiced. This outcome suggests that reduction of the Simon effect with practice is not due to strengthening the task-defined associations between the relevant letters and their assigned responses (or, in other words, to affecting the explicit $\mathrm{S}-\mathrm{R}$ translation), if it is assumed that the same amount of practice with the letters in a constant, centered location would produce equivalent strengthening. It is conceivable that less strengthening of the relevant $\mathrm{S}-\mathrm{R}$ association occurs when location does not vary than when it does, possibly because the task demands that less effort be devoted to it. However, the trends in overall RT and EP across sessions suggest that performance improved at least as much when the stimulus location was constant as when it varied, suggesting that any strengthening of the relevant $S-R$ association from practice was at least as large in the former case as in the latter. We think it more likely that the reduction of the Simon effect with practice reflects improved suppression of the irrelevant location information (or, in other words, of the automatic activation route), because the presence of this information is what differentiates the location-varying conditions of the Simon task from the location-constant conditions of the control task.

This interpretation is in agreement with the results obtained by Clawson (1994), using the Stroop color-naming task. In her study, one group of subjects received 400 trials at naming color stimuli. On a posttest involving naming of the same color stimuli, RTs were faster for this group than for a group who did not have the training. However, another part of the posttest showed that the training with the color stimuli did not reduce naming RTs for Stroop stimuli, nor did it have any impact on the magnitude of the Stroop effect. Clawson concluded that it is therefore likely that the reduction in the Stroop effect that occurs when the Stroop task itself is practiced involves decreased activation of the irrelevant information in response selection processes. Our Experiment 2 will provide converging evidence to support the hypothesis that im- proved suppression of the irrelevant location information is the basis for the reduction of the Simon effect.

\section{EXPERIMENT 2}

If the reduction of the Simon effect with practice is due to improved suppression of the irrelevant stimulus location information, responding should be impaired when stimulus location is subsequently made relevant. To evaluate this implication, two groups of subjects in Experiment 2 practiced for three sessions with the Simon task and then performed a fourth session in which stimulus location was the relevant dimension. In this fourth session, one of the groups performed with a spatially compatible $\mathrm{S}-\mathrm{R}$ mapping, and the other with a spatially incompatible mapping. If suppression of location information persists, responding should be slower and less accurate overall in the transfer session than it is for subjects who perform the spatial compatibility task without prior practice at the Simon task. Also of interest is whether the mapping effect is reduced in magnitude.

Two additional groups of subjects practiced with location relevant for the first three sessions, one group with a compatible S-R mapping and the other with an incompatible mapping. These subjects were transferred to the Simon task in the fourth session. This transfer condition allows examination of whether practice with the location dimension as relevant has an impact on performance when location subsequently is defined as irrelevant. Most explanations of the Simon effect attribute the effect to automatic activation of the corresponding response location (the bottom route of Figure 1) that is produced via longterm, or permanent, associative pathways (see, e.g., Barber \& O'Leary, 1997; De Jong et al., 1994; Zorzi \& Umiltà, 1995). Umiltà and Zorzi (1997) note that these long-term associations could be either truly permanent, in the sense that they are hard-wired genetically, or relatively permanent, having been learned from the many instances of associations between spatially corresponding stimulus and response locations that occur in every person's life. ${ }^{1}$ In the former case, practice with location relevant could not possibly alter the long-term associations; in the latter case, three sessions of practice are insignificant in comparison with the lifelong experience with spatially corresponding relations and, therefore, also should have little or no impact on the long-term associations.

Consequently, if only the long-term, permanent associations contribute to the Simon effect, an effect similar in magnitude to that obtained without prior practice should be found after practice with either the spatially compatible or the spatially incompatible mapping, and the Simon effects in these two conditions should not differ in magnitude. However, if the task-defined associations of stimulus locations to responses continue to contribute when stimulus location is no longer relevant to the task, the magnitude of the Simon effect in the transfer session should vary as a function of the prior mapping. Specifically, practice with an incompatible spatial map- 
ping should lead to a reversed Simon effect (faster responses when stimulus and response locations do not correspond than when they do), because the practice should strengthen the task-defined association between each stimulus location and the spatially noncorresponding response. Practice with a compatible spatial mapping should yield a Simon effect at least as large as that obtained normally. That is, such practice will reinforce the preexisting association of a stimulus location with the spatially corresponding response, but the influence of this practice may be minimal because the compatible relation is highly overlearned.

\section{Method \\ Subjects. Sixty-four students from the same introductory psy- chology pool as that in Experiment 1 participated, 16 in each of four conditions. \\ Apparatus, Stimuli, and Procedure. Stimuli were the letters $\mathrm{H}$ and $\mathrm{S}$ presented in left and right locations, as in the Simon task of Experiment 1. The subjects practiced for three sessions with let- ter identity relevant and stimulus location irrelevant (the Simon task) or stimulus location relevant and letter identity irrelevant (the spatial compatibility task). For the spatial compatibility task, half of the subjects used a compatible S-R mapping, whereas half used an incompatible $S-R$ mapping. In the fourth session, all the subjects were transferred to the task that they had not performed in the first three sessions. Half of the subjects who were transferred to the spa- tial compatibility task performed with a compatible mapping, and half with an incompatible mapping. The number of trials in each session was the same as that in Experiment 1, as was the counter- balancing of the assignment of letter identity to response location for the Simon task.}

\section{Results}

The mean RT and EP data are shown in Table 2.

Table 2

Mean Reaction Time in Milliseconds and Error Proportion (EP) in Experiment 2 as a Function of Correspondence, Session, and Task Order

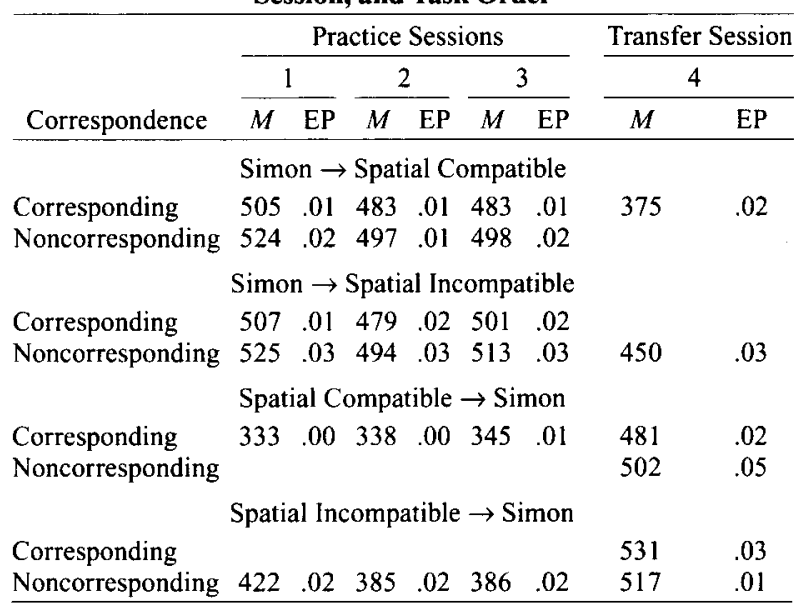

Note-The Simon $\rightarrow$ Spatial Compatible and Simon $\rightarrow$ Spatial Incompatible groups received the Simon task in Sessions 1-3 and the spatial compatibility task (with compatible or incompatible mapping) in Session 4. The Spatial Compatible $\rightarrow$ Simon and Spatial Incompatible $\rightarrow$ Simon groups received the spatial compatibility task (with compatible or incompatible mapping) in Sessions 1-3 and the Simon task in Session 4.
Practice. The subjects who participated in the Simon task for practice were partitioned according to whether they subsequently received the compatible or the incompatible spatial mapping in Session 4. The RT data showed main effects of session $\left[F(2,60)=3.30, M S_{\mathrm{e}}=14,276\right.$, $p<.05]$ and spatial correspondence $[F(1,30)=86.66$, $\left.M S_{\mathrm{e}}=544, p<.001\right]$. Mean RTs were 515, 488, and $499 \mathrm{msec}$ for Sessions 1, 2, and 3, respectively, and 493 and $509 \mathrm{msec}$ for corresponding and noncorresponding trials, respectively. The session $\times$ correspondence interaction was of borderline significance $[F(2,60)=3.03$, $\left.M S_{\mathrm{e}}=171, p=.056\right]$. The Simon effect tended to decrease across sessions as in Experiment 1, being $19 \mathrm{msec}$ in Session 1,15 msec in Session 2, and $13 \mathrm{msec}$ in Session 3 . No terms involving group were significant for the RT analysis.

The EP data for the subjects who practiced the Simon task showed a significant main effect of spatial correspondence $\left[F(1,30)=34.7, M S_{\mathrm{e}}=0.00041, p<.001\right]$ and a significant session $\times$ correspondence interaction $[F(2,60)$ $\left.=3.37, M S_{\mathrm{e}}=0.00031, p<.05\right]$. The error rate was less when stimulus and response locations corresponded than when they did not, and this difference was larger in the first session than in Sessions 2 and 3. One term involving group, the group $\times$ correspondence interaction, was significant $\left[F(1,30)=7.47, M S_{\mathrm{e}}=0.00031, p=.01\right]$. For unknown reasons, the group that was subsequently transferred to the compatible spatial mapping showed a larger Simon effect on error rate than did the group that was subsequently transferred to the incompatible spatial mapping.

For the groups who practiced the spatial compatibility task, there was a main effect of mapping $[F(1,30)=7.68$, $\left.M S_{\mathrm{e}}=45,252, p<.01\right]$ and a session $\times$ mapping interaction $\left[F(2,60)=4.31, M S_{\mathrm{e}}=4,671, p<.02\right]$. Overall, responses were $60 \mathrm{msec}$ faster with the spatially compatible mapping than with the incompatible mapping. This effect decreased across sessions, being $89 \mathrm{msec}$ in Session 1, $47 \mathrm{msec}$ in Session 2, and $41 \mathrm{msec}$ in Session 3, as is customarily found (e.g., Dutta \& Proctor, 1992). The error data showed only a nonsignificant tendency toward less accurate responding overall with the incompatible mapping than with the compatible mapping $[F(1,30)=$ $\left.3.03, M S_{\mathrm{e}}=0.00613, p<.10\right]$.

Transfer. The subjects who transferred from the Simon task to the spatial compatibility task in Session 4 showed significant mapping effects for both RTs $[F(1,30)=$ 9.06, $\left.M S_{\mathrm{e}}=19,984, p<.01\right]$ and errors $[F(1,30)=6.58$, $\left.M S_{\mathrm{e}}=0.00152, p<.02\right]$. The mapping effect for RTs was $75 \mathrm{msec}$. Compared with Session 1 of the group who practiced with the spatial compatibility task, the responses were slower and less accurate in the transfer session $\left[F \mathrm{~s}(1,60)=4.00\right.$ and $8.66, M S_{\mathrm{e}} \mathrm{s}=19,428$ and 0.00147 , $p=.05$ and $p<.005$, respectively]. Although the mapping effects tended to be smaller in the transfer session $(75 \mathrm{msec}$ and .01) than in Session 1 ( $89 \mathrm{msec}$ and .02), there was no interaction with mapping for either dependent measure $(F \mathrm{~S}<1)$. Thus, having to suppress responses to stimulus location when it was irrelevant to the task impaired performance overall when location was subsequently defined 
as relevant, but without significantly altering the magnitude of the mapping effect.

It is conceivable that performance in the spatial compatibility task would be affected by the previous mapping of letter identity to response. That is, for a given subject, each letter was associated with one of the two responses in the practice sessions. Therefore, there could be a tendency to make the response assigned to the particular letter that occurred on a trial when location is defined as relevant and letter identity as irrelevant in the transfer session. Unfortunately, no record was kept for the spatial compatibility task of whether the stimulus on a trial was an $\mathrm{S}$ or an $\mathrm{H}$. Consequently, the conditions in which the subjects practiced with the Simon task and switched to the spatial compatibility task were repeated with new subjects from the same subject pool. Twenty-four subjects were tested, with 12 using each mapping for the spatial compatibility task. In the transfer session, whether the letter occurred in the location corresponding to the response to which it had been assigned in practice had no influence on the pattern of S-R compatibility. RTs were virtually identical overall when the stimulus location was consistent with the previous assignment $(M=381 \mathrm{msec})$ and when it was not $(M=384 \mathrm{msec})$, and the compatibility effects were of similar magnitudes as well $(M=$ $65 \mathrm{msec}$ in both cases). The only significant effect in the analyses for both RTs and errors was the main effect of consistency for errors $\left[F(1,22)=4.63, M S_{\mathrm{e}}=0.00021\right.$, $p<.05]$. The EP was slightly higher $(M=.01)$ when the response to which the stimulus had been assigned during practice was inconsistent with the stimulus location than when it was consistent.

The major finding for the subjects who transferred from the spatial compatibility task to the Simon task was a group $\times$ correspondence interaction for both RTs $[F(1,30)$ $\left.=40.21, M S_{\mathrm{e}}=481, p<.001\right]$ and errors $[F(1,30)=$ 14.82, $\left.M S_{\mathrm{e}}=0.05584, p<.001\right]$. Separate analyses showed that, whereas the group who practiced with the spatially compatible mapping had a normal Simon effect of $21 \mathrm{msec}$ for RTs $\left[F(1,15)=40.04, M S_{\mathrm{e}}=360, p<\right.$ $.001]$ and .03 for EPs $\left[F(1,15)=7.86, M S_{\mathrm{e}}=0.00278\right.$, $p<.02]$, the group who practiced with the spatially incompatible mapping showed a reversed Simon effect of $14 \mathrm{msec}$ for RTs $\left[F(1,15)=9.77, M S_{\mathrm{e}}=603, p<.01\right]$ and of .02 for EPs $\left[F(1,15)=8.05, M S_{\mathrm{e}}=0.00095, p<\right.$ $.02]$. Thus, practicing with the incompatible spatial mapping reversed the Simon effect when spatial location was no longer relevant. In that case, responding was faster in the Simon task when stimulus location did not correspond with response location than when it did.

An obvious question of interest is whether the reversed Simon effect for the group who practiced with the incompatible spatial mapping was evident throughout the entire transfer session or whether there was a return to a typical Simon effect. Consequently, the transfer data for this group were partitioned into four blocks of 152 trials each. The magnitude of the reversed Simon effect tended to decrease across blocks for both the RT and the
EP data $(M \mathrm{~s}=22,16,7$, and $10 \mathrm{msec}$ and $.02, .02, .02$, and .01 for Blocks $1-4$, respectively). However, neither the RTs nor the EPs showed a significant block $\times$ correspondence interaction $\left[F \mathrm{~s}(3,45)=1.75\right.$ and $0.60, M S_{\mathrm{e}} \mathrm{s}=$ 212 and $0.00025, p s>.17]$, and the mean data never reverted to a positive Simon effect. Thus, the reversed Simon effect that occurs after practice with a spatially incompatible mapping is relatively persistent.

\section{Discussion}

The practice effects in Sessions 1-3 of Experiment 2 replicated those obtained for the Simon effect in Experiment 1 and for spatial S-R compatibility proper in earlier studies. Both the Simon effect and the S-R mapping effect decreased in magnitude but persisted across three sessions of practice encompassing more than 1,800 trials.

Prior practice with the Simon task, for which stimulus location is irrelevant, had little influence on the S-R mapping effect for the spatial compatibility task. Responses were slower and less accurate with the spatially incompatible mapping than with the spatially compatible mapping, and the magnitude of this mapping effect in the transfer session was not significantly less than that in Session 1 for the subjects who practiced the spatial compatibility task. This outcome suggests that response selection for the spatial compatibility task in the transfer session was based on spatial coding that operated much as normal.

Although the magnitude of the S-R mapping effect was not affected significantly by the prior practice with the Simon task, responding was slower and less accurate overall in the transfer session than it was when the spatial compatibility task was performed initially. This result provides stronger evidence than did Experiment 1 that the reduction in the Simon effect with practice involves suppressing the irrelevant location information. Even when stimulus location subsequently was made relevant, it was difficult to base the response on that stimulus dimension. Again, similar results have been obtained for the Stroop color-naming task. The subjects in Stroop's (1935/1992) Experiment 3 who practiced the Stroop colornaming task for eight sessions were considerably slower in a posttest in which the color word was to be read and the ink color ignored than they had been in a pretest of this task.

The subjects who practiced the spatial compatibility task with a compatible mapping showed a Simon effect of typical initial magnitude in the transfer session. In contrast, the subjects who practiced with an incompatible mapping showed a reversed Simon effect of an only slightly smaller magnitude. Because the transfer session included 600 trials, the inclination to respond at the spatially noncorresponding location must be relatively robust to be evident in the mean data. This robustness was confirmed by an analysis showing that, although the reversed Simon effect tended to decrease in magnitude across the transfer session, it did not revert to an advantage for the spatially corresponding location. These results 
clearly indicate that the task-defined associations between stimulus and response locations continue to affect performance for some time after the task requirements have changed.

\section{EXPERIMENT 3}

In Experiment 2, the Simon effect was reversed by prior practice at responding to location as the relevant stimulus dimension. In that experiment, the stimuli used in practice (the letters $\mathrm{S}$ and $\mathrm{H}$ ) were the same as those used in the final session. The issue of how tightly location information is bound to identity information has been the subject of research in several areas of visual information processing (e.g., Johnston \& Pashler, 1990; Park \& Kanwisher, 1994). In the present context, this issue is whether the task-defined associations of spatially incompatible stimulus and response locations that are strengthened through practice when stimulus location is relevant are specific to the stimuli that are used in practice or are independent of them. In Experiment 3, this specificity issue was evaluated by having subjects practice responding to location using an incompatible mapping either with the letter stimuli or with color stimuli (red or green circles). In the final session, all the subjects were tested with the letter stimuli. If location becomes associated with the assigned response independent of the relevant stimulus dimension, the reverse Simon effect should be equally evident for both groups of subjects in the last session.

\section{Method}

Subjects. Thirty-two students from the same introductory psychology pool as that for the previous experiments participated in four sessions.

Apparatus, Stimuli, and Procedure. The apparatus was the same as that in previous experiments. The subjects practiced the spatial compatibility task for three sessions with an incompatible mapping, using either the letters $\mathrm{S}$ and $\mathrm{H}$, as in Experiments 1 and

Table 3

Mean Reaction Time in Milliseconds and Error Proportions (EP) in Experiment 3 as a Function of Relevant Stimulus Dimension (Colors, Letters), Correspondence, and Session

\begin{tabular}{|c|c|c|c|c|c|c|c|c|}
\hline \multirow[b]{3}{*}{ Correspondence } & \multicolumn{6}{|c|}{ Practice Sessions } & \multirow{2}{*}{\multicolumn{2}{|c|}{$\frac{\text { Transfer Session }}{4}$}} \\
\hline & \multicolumn{2}{|c|}{1} & \multicolumn{2}{|c|}{2} & \multicolumn{2}{|c|}{3} & & \\
\hline & $M$ & EP & $M$ & EP & $M$ & $\mathrm{EP}$ & $M$ & $\mathrm{EP}$ \\
\hline \multicolumn{9}{|c|}{ Letters $\rightarrow$ Letters } \\
\hline Corresponding & & & & & & & 512 & .03 \\
\hline Noncorresponding & 408 & .03 & 390 & .02 & 390 & .01 & 487 & .01 \\
\hline \multicolumn{9}{|c|}{ Colors $\rightarrow$ Letters } \\
\hline Corresponding & & & & & & & 513 & .03 \\
\hline Noncorresponding & 407 & .01 & 378 & .01 & 366 & .01 & 483 & .01 \\
\hline
\end{tabular}

Note-Both groups performed the spatial compatibility task with an incompatible spatial mapping in Sessions $1-3$ and the Simon task in Session 4. For the Letters $\rightarrow$ Letters group, the stimuli were the letters $\mathrm{S}$ and $\mathrm{H}$ in all four sessions. For the Colors $\rightarrow$ Letters group, the stimuli were the colored circles red and green in Sessions 1-3 and the letters $\mathrm{S}$ and $\mathrm{H}$ in Session 4.
2 , or the colors red and green. The color stimuli were filled circles (MEL code C7) that were of either a red (MEL color code +4 ) or a green (MEL color code +2 ) color. When viewed from a distance of approximately $55 \mathrm{~cm}$, the visual angle subtended by each color stimulus was $0.74^{\circ}$. In the fourth session, all the subjects performed the Simon task with $\mathrm{S}$ and $\mathrm{H}$ as stimuli. Each practice session and the test session consisted of only a single block of 4 practice trials and 304 test trials, making the amount of practice prior to transfer half of what it was in Experiments 1 and 2.

\section{Results}

The mean RT and EP data are shown in Table 3.

Practice with incompatible spatial mapping. RTs showed only a main effect of session $[F(2,60)=13.08$, $\left.M S_{\mathrm{e}}=600, p<.001\right]$. Mean RTs were 408, 384, and $378 \mathrm{msec}$ in Sessions 1, 2, and 3, respectively. Neither stimulus type $(F<1.0)$ nor the interaction of stimulus type with session $\left[F(2,60)=1.75, M S_{\mathrm{e}}=35,994, p=.18\right]$ was significant. For EPs, the main effect of session was significant $\left[F(2,60)=20.60, M S_{\mathrm{e}}=0.00004, p<.001\right]$, as was the session $\times$ stimulus set interaction $[F(2,60)=$ $\left.5.74, M S_{\mathrm{e}}=0.00004, p<.01\right]$. Error rate decreased across sessions, with this decrease occurring primarily for the letter stimulus set.

Transfer. For the fourth session, a reliable reversed Simon effect was obtained for both RTs [ $M=27 \mathrm{msec}$; $\left.F(1,30)=26.25, M S_{\mathrm{e}}=13,602, p<.001\right]$ and $\mathrm{EPs}[M=$ $\left..02 ; F(1,30)=15.66, M S_{\mathrm{e}}=0.01026, p<.001\right]$. Neither the main effect of stimulus set used in practice nor the interaction of this factor with spatial correspondence was significant for either RTs or errors $(F \mathrm{~s}<1.0)$. For the subjects who practiced with colors, RT was $513 \mathrm{msec}$ when stimulus location corresponded with response location and $483 \mathrm{msec}$ when it did not; for the subjects who practiced with letters, the RTs were 512 and $487 \mathrm{msec}$, respectively. When partitioned into two 152 trial blocks, the reversed Simon effects for both RTs and EPs were found to persist across the two blocks, although the effect for RTs tended to decrease slightly $[M \mathrm{~s}=30$ and $24 \mathrm{msec}$ and .02 and .02 , for Blocks 1 and 2 , respectively; $F \mathrm{~s}(1,30)$ $=3.83$ and $1.05, M S_{\mathrm{e}} \mathrm{s}=230$ and $0.00030, p \mathrm{~s}=.06$ and .31 , respectively].

\section{Discussion}

The results of Experiment 3 are relatively unambiguous. The task-defined associations of stimulus locations with response locations that are strengthened when performing with an incompatible spatial mapping during practice are independent of the symbolic content of the stimuli. Whether the stimulus dimension is the same in practice as at test or different, when stimulus location is subsequently made irrelevant, it is the spatially incompatible response that appears to be automatically activated, rather than the compatible response. Experiment 3 also demonstrates that it is not necessary to have 1,800 trials of practice (as in Experiment 2) to obtain the reversed Simon effect, as the effect was found with half that amount of practice. 


\section{EXPERIMENT 4}

The reversal of the Simon effect obtained after practice at responding to location with an incompatible mapping is reminiscent of the Hedge and Marsh (1975) reversal. As was described in the introduction, Hedge and Marsh had subjects perform a Simon task using colored stimuli but with the response keys labeled according to color. This allowed them to use an incongruent mapping for the relevant color dimension (i.e., press the "green" key to the red stimulus, and vice versa). With the incongruent color mapping, a reversed Simon effect was obtained. Responding was faster when the stimulus occurred in the location that did not correspond to the response.

Although the reversal phenomenon that was obtained following transfer from an incompatible spatial mapping in Experiments 2 and 3 is superficially similar to that obtained with an incompatible color mapping in the Hedge and Marsh (1975) task, there is an important difference between the two situations. In the transfer situation, the irrelevant location dimension was previously relevant, and the spatial mapping defined for the previous task continues to affect performance after location is no longer relevant. In the Hedge and Marsh situation, location was not defined as relevant previously, so the reversal cannot be attributed to a prior spatial mapping intruding into performance.

De Jong et al. (1994) proposed that there are two components to the Hedge and Marsh (1975) reversal. The reversal itself is due to a logical recoding transformation of the type proposed originally by Hedge and Marsh - that is, a goal-dependent transformation of stimulus location that is unintended. In other words, the explicit $\mathrm{S}-\mathrm{R}$ translation rule respond with opposite value that is appropriate for the relevant color dimension when the mapping is incongruent gets applied inappropriately to the irrelevant stimulus location dimension. The effect of this component is independent of the point in time after stimulus onset at which the recoding occurs. The other component is automatic activation of the spatially corresponding response, independent of the task goal. This activation, which counters the reversal produced by the first component when the relevant $\mathrm{S}-\mathrm{R}$ mapping is incongruent, occurs quickly but then decays. The combination of these two components accounts for why the magnitude of the reversed Simon effect increases, rather than decreases, with time.

In Experiment 4, the relation between the reversal of the Simon effect that occurs after practice responding to stimulus location with an incompatible mapping and the reversal that occurs in the Hedge and Marsh (1975) task was examined. After three sessions of practice with a spatially incompatible mapping, the subjects switched to the Hedge and Marsh task, half using a congruent S-R mapping and half an incongruent mapping for the relevant stimulus dimension. Within the context of De Jong et al.'s (1994) framework, there are at least two different ways in which prior practice with a spatially incompatible mapping could affect performance in the Hedge and Marsh task.
First, practice could affect the spatial code to which the logical recoding rule is applied. That is, instead of the rule being applied to the code corresponding to stimulus location, it could be applied to the noncorresponding spatial code. If so, a reversed Simon effect would be obtained for the congruent mapping condition in the Hedge and Marsh (1975) task, much as in the basic Simon task, but a positive Simon effect would be obtained for the incongruent mapping condition (i.e., the noncorresponding spatial code would be reversed to be the corresponding spatial code). The second possibility is that the automatic activation component, although independent of the current task goal, is not permanent but is a function of the task-defined association that was established previously. In this case, the prior practice with an incongruent spatial mapping should add a reversal component to both versions of the Hedge and Marsh task, resulting in a reversed Simon effect for the congruent mapping, again as in the standard Simon task, but an even larger reversed effect for the incongruent mapping. The distinguishing result, thus, is whether the incongruent mapping shows a standard Simon effect or a larger reversed Simon effect in comparison with the congruent mapping.

\section{Method}

Subjects. Thirty-two subjects, 16 in each of two groups, from the same pool as that in the previous experiments participated.

Apparatus, Stimuli, and Procedure. The apparatus was the same as that in the previous experiments, and the session lengths were the same as those in Experiment 3. The subjects practiced for three sessions with the color circle stimuli used in that experiment but were responding to stimulus location with a spatially incompatible mapping. In the fourth session, they were transferred to the Hedge and Marsh (1975) task, using S and $\mathrm{H}$ as stimuli. Tags with the letters $\mathrm{S}$ and $\mathrm{H}$ were placed below the display screen, immediately above their respective response keys, to identify the keys. For half of the subjects in each group, the left key was labeled $S$ and the right key $\mathrm{H}$, and for the other half these labels were reversed. The letter mapping in the transfer session was either congruent (respond with the key labeled $S$ if the stimulus is $S$ and the key labeled $H$ if the stimulus is $\mathrm{H}$ ) or incongruent (respond with the key labeled $\mathrm{H}$ if the stimulus is $\mathrm{S}$ and the key labeled $\mathrm{S}$ if the stimulus is $\mathrm{H}$ ).

\section{Results}

Practice with incompatible spatial mapping. Both RTs and errors showed main effects of session $[F \mathrm{~s}(2,62)=$ 8.73 and $7.27, M S_{\mathrm{e}} s=1,684$ and $0.00126, p \mathrm{~s}<.002$, respectively]. RTs decreased across sessions $(M \mathrm{~s}=403$, 395 , and $374 \mathrm{msec}$ for Sessions 1-3, respectively), as did $\operatorname{EPs}(M \mathrm{~s}=.025, .021$, and .016 for Sessions 1-3).

\section{Table 4}

Mean Reaction Time in Milliseconds and Error Proportion (EP) in Session 4 of Experiment 4 as a Function of Spatial Correspondence and Mapping (Congruent, Incongruent) for the Relevant Letter Identity Dimension

\begin{tabular}{|c|c|c|c|c|}
\hline \multirow{3}{*}{$\begin{array}{c}\text { Spatial } \\
\text { Correspondence }\end{array}$} & \multicolumn{4}{|c|}{ Letter Mapping } \\
\hline & \multicolumn{2}{|c|}{ Congruent } & \multicolumn{2}{|c|}{ Incongruent } \\
\hline & $M$ & $E P$ & $M$ & EP \\
\hline Corresponding & 521 & .01 & 559 & .06 \\
\hline Noncorresponding & 504 & .02 & 519 & .03 \\
\hline
\end{tabular}


Transfer. The mean RT and EP data for the transfer session are shown in Table 4. The main effect of spatial correspondence was significant for both RTs and errors $\left[F \mathrm{~s}(1,30)=26.96\right.$ and $20.88, M S_{\mathrm{e}} \mathrm{s}=877$ and 0.00098 , $p \mathrm{~s}<.001$, respectively]. These effects reflect a reversed Simon effect for which the responses were faster and more accurate when the stimulus location did not correspond with that of the response than when it did. However, spatial correspondence interacted with letter mapping for both RTs and errors $[F \mathrm{~s}(1,30)=4.70$ and $8.61, p \mathrm{~s}=.038$ and .006]. The reversed Simon effect was larger for the subjects responding with the incongruent letter mapping (38 msec and .05), which typically produces a reversed Simon effect, than for those responding with the congruent letter mapping ( $15 \mathrm{msec}$ and .01 ), which typically produces a normal Simon effect. Thus, the reversal attributable to the mapping rule was added to that attributable to practice.

When the data were partitioned into two 152-trial blocks, a three-way interaction of block $\times$ correspondence $\times$ mapping was significant for the $\operatorname{RTs}[F(1,30)=8.41$, $\left.M S_{\mathrm{e}}=218, p=.007\right]$ but not for the EPs $(F<1.0)$. For the subjects who practiced with the incongruent mapping, the reversed Simon effect decreased from 49 to $29 \mathrm{msec}$ across blocks $\left[F(1,15)=8.36, M S_{\mathrm{e}}=204, p=.011\right]$. For the subjects who practiced with the congruent spatial mapping, the reversed effect showed a nonsignificant tendency to increase from 11 to $21 \mathrm{msec}$ across blocks $[F(1,15)=$ $\left.1.59, M S_{\mathrm{e}}=232, p=.226\right]$. For this latter group, the difference for errors tended to decrease from Block 1 to Block $2\left[F(1,15)=3.65, M S_{\mathrm{e}}=0.00011, p=.075\right]$, suggesting that the tendency for RT disparity to increase reflects only a change in speed-accuracy criterion.

\section{Discussion}

The Hedge and Marsh (1975) task differs from the standard Simon task in that the relevant stimulus dimension, in this case letter identity, can be mapped to the responses in a congruent or an incongruent manner. The congruent mapping of the relevant dimension typically yields a standard Simon effect. Unsurprisingly, then, the results obtained with the congruent mapping of the relevant dimension after three sessions of practice with a spatially incompatible mapping were similar to those found for the Simon task in Experiments 2 and 3: A reversed Simon effect of $15 \mathrm{msec}$ was obtained in the transfer session for the congruent version of the Hedge and Marsh task.

More important is what happens in the incongruent version of the Hedge and Marsh (1975) task, which normally produces a reversed Simon effect. The magnitude of the reversed Simon effect was substantially larger for the incongruent version of the Hedge and Marsh task than for the congruent version. This outcome is consistent with the view that practice with a spatially incompatible mapping results in automatic activation of the opposite response location when stimulus location subsequently becomes irrelevant. This activation adds to the component attributable to unintentional application of the task-defined recoding transformation to the spatial stimulus code, resulting in a large reversed Simon effect when the Hedge and Marsh task is performed with an incongruent mapping. Thus, as with the previous experiments, the results of Experiment 4 imply that a response assigned to a stimulus location in a prior task continues to receive activation when a stimulus occurs in that location, even though stimulus location is no longer relevant.

\section{GENERAL DISCUSSION}

Performance of most tasks typically improves with practice, and practice can benefit many aspects of information processing. In tasks that require choice reactions to stimuli displayed in isolation, the benefits of practice are usually attributed primarily to response selection processes (see, e.g., Teichner \& Krebs, 1974). When responding to stimulus location, practice has been shown to reduce but not eliminate the magnitude of spatial compatibility effects (see, e.g., Dutta \& Proctor, 1992). Because response selection is more difficult initially for incompatible spatial S-R mappings than for compatible ones, the former mappings benefit relatively more than do the latter from improvements in response selection efficiency from practice.

\section{Reduction and Persistence of the Simon Effect With Practice}

Stimulus location also affects response selection when location is defined as irrelevant, as in the Simon task in which the stimulus can occur in a left or a right location but the correct response is signaled by a symbolic stimulus property such as letter identity. Responses are faster and more accurate when the stimulus occurs in the location that corresponds with its assigned response than when it occurs in the noncorresponding location. Hommel (cited in Prinz et al., 1995) and Simon et al. (1973) showed an effect of practice for the Simon effect that was similar to that found in studies of $S-R$ compatibility proper. The Simon effect was reduced but not eliminated by practice at the task.

The studies of Hommel (cited in Prinz et al., 1995) and Simon et al. (1973), however, used auditory stimuli, which typically yield a Simon effect (i.e., a spatial correspondence effect) of approximately twice the magnitude of that obtained in the more common task version that uses visual stimuli (see, e.g., Umiltà \& Nicoletti, 1990). Experiments 1 and 2 of the present study demonstrate that, despite the initially smaller size of the Simon effect for visual stimuli, the influence of practice shows a pattern similar to that for the Simon effect with auditory stimuli. The Simon effect produced in Experiments 1 and 2 when responding to the identity of visually presented letters in left or right locations decreased from its initial value but persisted at a reduced magnitude for at least 1,800 trials.

This persisting influence of irrelevant location information as subjects become practiced at a task is not only 
in agreement with the studies of the auditory Simon task but also with studies using visual stimuli that have examined other types of irrelevant information. For example, when a target letter is flanked in irrelevant locations by instances of a letter from the same set, responses typically are faster when the flanker and target identities correspond in terms of the response that each indicates than when they do not (see, e.g., Eriksen \& Eriksen, 1974). This effect, known as the Eriksen flanker effect, has been shown to persist with little change in magnitude across four sessions of approximately 300 trials each (Proctor \& Fober, 1988). Also, the Stroop effect for color naming, in which naming of the ink color of a form is slowed when the form spells an irrelevant color word, has been shown to decrease with practice but not to disappear (see, e.g., Clawson et al., 1995; Stroop, 1935/1992), as has a version of the Stroop effect in which reading location words (left, right, up, down) was slowed when they were printed inside irrelevant arrows that pointed in conflicting directions (Shor, Hatch, Hudson, Landrigan, \& Shaffer, 1972). Thus, a general principle of human information processing is that effects of irrelevant information may be reduced with practice at a task but are not typically eliminated.

\section{Basis for the Reduction of the Simon Effect}

The reduction in magnitude of the Simon effect that occurs as a function of practice apparently requires that location vary in an irrelevant manner. When the letter stimuli were presented in a constant, centered location for the three practice sessions in Experiment 1, performance of the Simon task in the fourth session was similar to that in the first session for the subjects who practiced the Simon task in the first three sessions. This outcome suggests that strengthening of the task-def ined relevant $S-R$ associations alone is not sufficient to reduce the effect of irrelevant location. An account in terms of strengthening the relevant $S-R$ associations could be retained, if it is assumed that less strengthening of these associations occurred when location was constant than when it was varied. However, the trends in the overall mean RTs across sessions suggest that the improvement in performance was at least as great when location was constant as when it varied, thus arguing against the possibility that the relevant $\mathrm{S}-\mathrm{R}$ associations were strengthened less when stimulus location was constant. More likely, the reduction of the Simon effect that occurs with practice involves learning to ignore or suppress the irrelevant location information to some extent.

In Experiment 2, results were obtained that were consistent with this interpretation of the results of Experiment 1 . The subjects who practiced the Simon task (in which letter identity was the relevant stimulus dimension) for three sessions showed slower and less accurate responses when location was defined as relevant in the fourth session than did the subjects who began the experiment with location as relevant. Having practiced attending to letter identity and ignoring stimulus location appar- ently made it difficult subsequently to attend to stimulus location. However, the magnitude of the spatial mapping effect was not influenced significantly by this practice. Thus, although access to the relevant stimulus location information was impaired by prior practice with a task in which location was irrelevant, the coding of this information in response selection was relatively unaffected.

An additional finding for the subjects who transferred to the spatial compatibility task from the Simon task in Experiment 2 was that the RTs to stimulus location were not influenced by the relation between letter identities and responses that had been practiced during the Simon task. The prior letter-response mapping was not completely insignificant, however, because incorrect responses were fewer when the irrelevant letter identity indicated the same response as that specified by the relevant stimulus location dimension. It is likely that the relatively minor impact on performance of changing the previously relevant letter-identity dimension to irrelevant is a consequence of the relation between alphanumeric stimuli and response location being relatively indirect (see, e.g., Lu, 1997).

\section{Influence of Prior Spatial Mapping on the Simon Effect}

When stimulus location is relevant during practice, its impact when it is subsequently irrelevant in the transfer session is much more pervasive. In both Experiment 2 and Experiment 3, practice with an incompatible spatial mapping led to a reversed Simon effect when stimulus location was subsequently defined as irrelevant. That is, in the transfer session, responses were slower when the stimulus location corresponded with that of the response than when it did not. This outcome occurred regardless of whether or not the stimuli were the same in practice as in transfer, indicating that the acquired task-defined associations of S-R locations are independent of the specific stimuli used to designate the locations.

Experiment 4 demonstrated that the tendency to make the noncorresponding response that arises from prior practice with a spatially incompatible mapping adds to the reversal of the Simon effect that occurs when an incongruent mapping of letter identity to the identities of labeled response keys is used in the Hedge and Marsh (1975) task variation. This outcome is consistent with the implication of Experiments 2 and 3 that, after practice with an incompatible spatial mapping, a stimulus automatically activates the response at the noncorresponding location. This activation (by way of the bottom route of Figure 1) appears to be distinct from the tendency to respond at the opposite location that is produced by misapplication of the logical recoding reversal rule to the irrelevant stimulus location attribute (by way of the top route of Figure 1).

Most accounts of the Simon effect attribute the effect to automatic activation, via long-term associations, of the response location that corresponds spatially to the stimulus location (see, e.g., Barber \& O'Leary, 1997; De 
Jong et al., 1994; Lu, 1997; Zorzi \& Umiltà, 1995). These associations have been described as unconditional (De Jong et al., 1994), permanent (Barber \& O'Leary, 1997), and as being either hard-wired or learned from a lifetime's experience (Umiltà \& Zorzi, 1997). The implication of such descriptions - that the associations are essentially unmodifiable-is incorrect. As is illustrated by the reversal of the Simon effect after practice with an incompatible spatial mapping, the response that is activated automatically when stimulus location is irrelevant to the task is highly dependent on temporary associations between stimulus and response locations that were defined specifically for performance of a prior task. Put another way, although the distinction between task-defined associations and long-term associations seems valid, the influence of task-defined associations on performance extends well beyond the period during which they can be presumed to be held in an active state because of the instructions that are in effect. This finding seems to be particularly congenial to theories of automatization that characterize it in terms of the retrieval of stored memories (e.g., Logan, 1988; Schneider, 1985). Because the recent memories would be of the spatial mapping that was practiced before being switched to the Simon task, this mapping, rather than preexperimental dispositions, should determine which response is activated automatically in response to the stimulus location.

\section{Pliability of the Simon Effect}

The major point illustrated by the present study is that the influence of irrelevant location on performance is highly dependent on the immediately preceding experience. When that experience involves practice of the same task, the Simon effect produced by the irrelevant information is reduced in magnitude. When the experience involves responding to stimulus location with a spatially incompatible mapping, the Simon effect obtained when location is made irrelevant to the task reverses its sign. Instead of responses being faster when stimulus and response locations correspond, responses are faster when the locations do not correspond. Perhaps even more surprising, this reversal persists over at least 600 trials, so it is relatively robust with respect to practice at the Simon task.

The pliability of the Simon effect demonstrated here adds to demonstrations of its reversal with an incongruent mapping of the relevant stimulus dimension to the responses (Hedge \& Marsh, 1975) and with instructions to turn on a light at the location opposite the key that is to be pressed (Hommel, 1993a). However, the reversals in the prior studies have been a consequence of the task goals conveyed by the instructions given the subject. What is unique about the present case is that the reversal occurs with the standard instructions for the Simon task and is a function of prior mappings intruding on performance. The specific response that is activated automatically by an irrelevant stimulus location attribute is not relatively invariant, as is often implied (e.g., Barber \& O'Leary, 1997; Umiltà \& Zorzi, 1997), but varies as a function of mappings that were in effect for a preceding task. In sum, the effect of irrelevant location information on performance is a function not only of the goals for the task that is currently being performed but also of the ways in which this information was responded to when it was relevant in the immediate past.

\section{REFERENCES}

BARBER, P., \& O'LEARY, M. (1997). The relevance of salience: Towards an activational account of irjelevant stimulus-response compatibility effects. In B. Hommel \& W. Prinz (Eds.), Theoretical issues in stimulus-response compatibility (pp. 135-172). Amsterdam: NorthHolland.

Brebner, J., Shephard, M., \& Cairney, P. (1972). Spatial relationships and S-R compatibility. Acta Psychologica, 37, 93-106.

Carlson, R. A., Khoo, B. H., Yaure, R. G., \& Schnelder, W. (1990). Acquisition of a problem-solving skill: Levels of organization and use of working memory. Journal of Experimental Psychology: General, 119, 193-214.

Clawson, D. M. (1994). Dimensions of practice specificity in the classic Stroop color-word task. Unpublished doctoral dissertation, University of Colorado, Boulder.

Clawson, D. M., King, C. I., Healy, A. F., \& Ericsson, K. A. (1995) Training and retention of the classic Stroop task. In A. F. Healy \& L. E. Bourne, Jr. (Eds.), Learning and memory of knowledge and skills. Durability and specificity (pp. 234-254). Thousand Oaks, CA: Sage.

COHEN, A., IVRY, R. I., \& KEELE, S. W. (1990). Attention and structure in sequence learning. Journal of Experimental Psychology: Learning, Memory, \& Cognition, 16, 17-30.

De Jong, R., Liang, C.-C., \& Lauber, E. (1994). Conditional and unconditional automaticity: A dual-process model of effects of spatial stimulus-response correspondence. Journal of Experimental Psychology: Human Perception \& Performance, 20, 731-750.

DutTA, A., \& Proctor, R. W. (1992). Persistence of stimulus-response compatibility effects with extended practice. Journal of Experimental Psychology: Learning, Memory, \& Cognition, 18, 801-809.

DutTa, A., \& Proctor, R. W. (1993). The role of feedback in learning spatially indirect choice reaction tasks: Does it have one? In Proceedings of the Human Factors and Ergonomics Society 37th Annual Meeting (pp. 1320-1324). Santa Monica, CA: Human Factors and Ergonomics Society.

ERIKSEN, B. A., \& ERIKSEN, C. W. (1974). Effects of noise letters upon the identification of a target letter in a nonsearch task. Perception $\&$ Psychophysics, 16, 143-149.

FitTs, P. M., \& Posner, M. I. (1967). Human performance. Belmont, CA: Brooks/Cole.

Fitts, P. M., \& SeEger, C. M. (1953). S-R compatibility: Spatial characteristics of stimulus and response codes. Journal of Experimental Psychology, 46, 199-210.

Gopher, D., BrickNer, M., \& NAvON, D. (1982). Different difficulty manipulations interact differently with task emphasis: Evidence for multiple resources. Journal of Experimental Psychology: Human Perception \& Performance, 8, 146-157.

HasbroucQ, T, \& Guiard, Y. (1991). Stimulus-response compatibility and the Simon effect: Toward a conceptual clarification. Journal of Experimental Psychology: Human Perception \& Performance, 17, 246-266.

HEALY, A. F., \& Bourne, L. E., JR. (EDS.) (1995). Learning and memory of knowledge and skills: Durability and specificity. Thousand Oaks, CA: Sage.

HedGe, A., \& MARSH, N. W. A. (1975). The effect of irrelevant spatial correspondences on two-choice response-time. Acta Psychologica, 39, 427-439

HoMmEL, B. (1993a). Inverting the Simon effect by intention: Determinants of direction and extent of effects of irrelevant spatial information. Psychological Research, 55, 270-279.

HoMmel, B. (1993b). The relationship between stimulus processing and response selection in the Simon task: Evidence for a temporal overlap. Psychological Research, 55, 280-290.

Hommer, B. (1995). Stimulus-response compatibility and the Simon effect: Toward an empirical clarification. Journal of Experimental Psychology: Human Perception \& Performance, 21, 764-775. 
Hommel, B., \& PRINZ, W. (EDS.)(1997). Theoretical issues in stimulusresponse compatibility. Amsterdam: North-Holland.

Johnston, J. C., \& PAShler, H. (1990). Close binding of identity and location in visual feature perception. Journal of Experimental Psychology: Human Perception \& Performance, 16, 843-856.

Kornblum, S., HasbroucQ, T., \& Osman, A. (1990). Dimensional overlap: Cognitive basis for stimulus-response compatibility-A model and taxonomy. Psychological Review, 97, 253-270.

LOGAN, G. D. (1988). Toward an instance theory of automatization. Psychological Review, 95, 492-527.

LOGAN, G. D. (1990). Repetition priming and automaticity: Common underlying mechanisms? Cognitive Psychology, 22, 1-35.

Lu, C.-H. (1997). Correspondence effects for irrelevant information in choice-reaction tasks: Characterizing the S-R relations and the processing dynamics. In B. Hommel \& W. Prinz (Eds.), Theoretical issues in stimulus-response compatibility (pp. 85-117). Amsterdam; North-Holland.

Lu, C.-H., \& Proctor, R. W. (1994). Processing of an irrelevant location dimension as a function of the relevant stimulus dimension. Journal of Experimental Psychology: Human Perception \& Performance, 20, 286-298.

Lu, C.-H., \& Proctor, R. W. (1995). The influence of irrelevant location information on performance: A review of the Simon and spatial Stroop effects. Psychonomic Bulletin \& Review, 2, 174-207.

Nicoletti, R., Anzola, G. P., Luppino, G., Rizzolatti, G., \& UMILTÀ, C. (1982). Spatial compatibility effects on the same side of body midline. Journal of Experimental Psychology: Human Perception \& Performance, 8, 664-673.

Park, J., \& Kanwisher, N. (1994). Determinants of repetition blindness. Journal of Experimental Psychology: Human Perception \& Performance, 20, 500-519.

Pashler, H., \& Baylis, G. (1991). Procedural learning: 1. Locus of practice effects in speeded choice tasks. Journal of Experimental Psychology: Learning, Memory, \& Cognition, 17, 20-32.

Pellegrino, J. W., Doane, S. M., Fischer, S. C., \& Alderton, D. (1991). Stimulus complexity effects in visual comparisons: The effects of practice and learning context. Journal of Experimental Psychology: Human Perception \& Performance, 17, 781-791.

Prinz, W., Aschersleben, G., Hommel, B., \& Vogt, S. (1995). Handlungen als Ereignisse [Actions as events]. In D. Dörner \& E. van der Meer (Eds.), Gedächtnis: Trends, Probleme, Perspektiven (pp. 129168). Göttingen: Hogrefe

Proctor, R. W., \& DutTA, A. (1993). Do the same stimulus-response relations influence choice reactions initially and after practice? Journal of Experimental Psychology: Learning, Memory, \& Cognition, 19, 922-930.

Proctor, R. W., \& DutTA, A. (1995). Skill acquisition and human performance. Thousand Oaks, CA: Sage.

Proctor, R. W., \& FoBer, G. W. (1988). A response-selection basis for the mixed-category, repeated-stimulus inferiority effect. Perception $\&$ Psychophysics, 44, 182-190.

Proctor, R. W., \& Lu, C.-H. (1994). Referential coding and attention shifting accounts of the Simon effect. Psychological Research, 56, 185-195.

Proctor, R. W., \& ReEve, T. G. (Eds.) (1990). Stimulus-response compatibility: An integrated perspective. Amsterdam: North-Holland.

Proctor, R. W., Van Zandt, T., Lu, C.-H., \& Weeks, D. J. (1993). Stimulus-response compatibility for moving stimuli: Perception of affordances or directional coding? Journal of Experimental Psychology: Human Perception \& Performance, 19, 81-91.

Proctor, R. W., \& WANG, H. (1997). Enhancement of the Simon effect by response-location precues: Evaluation of the stimulus identification account. Acta Psychologica, 95, 279-298.

RabBitT, P. M. A. (1989). Sequential reactions. In D. H. Holding (Ed.), Human skills (2nd ed., pp. 147-170). New York: Wiley.

Reisberg, D., Baron, J., \& KemLer, D. G. (1980). Overcoming Stroop interference: The effects of practice on distractor potency. Journal of Experimental Psychology: Human Perception \& Performance, 6, 140-150.

RIDDERINKHOF, K. R. (1997). Commentary on Lu: A dual-route processing architecture for stimulus-response correspondence effects. In B. Hommel \& W. Prinz (Eds.), Theoretical issues in stimulusresponse compatibility' (pp. 119-129). Amsterdam: North-Holland.
Rosenbloom, P. S., \& Newell, A. (1987). An integrated computational model of stimulus-response compatibility and practice. In G. H. Bower (Ed.), The psychology of learning and motivation (Vol. 21, pp. 1-52). New York: Academic Press.

Roswarski, T. E., \& Proctor, R. W. (1996). Multiple spatial codes and temporal overlap in choice-reaction tasks. Psychological Research, 59, 196-211.

SCHNEIDER, W. (1985). Toward a model of attention and the development of automatic processing. In M. I. Posner \& O. S. M. Marin (Eds.), Attention and performance XI (pp. 475-492). Hilisdale, NJ: Erlbaum

SCHNEIDER, W. (1988). Micro Experimental Laboratory: An integrated system for IBM PC compatibles. Behavior Research Methods, Instruments, \& Computers, 20, 206-217.

ShIFFrin, R. M., \& SchneIder, W. (1977). Controlled and automatic human information processing: II. Perceptual learning, automatic attending, and a general theory. Psychological Review, 84, 127-190.

Shor, R. E., Hatch, R. P., Hudson, L. J., Landrigan, D. T., \& ShaFFER, H. J. (1972). Effect of practice on a Stroop-like spatial directions task. Journal of Experimental Psychology, 94, 168-172.

Simon, J. R. (1990). The effects of an irrelevant directional cue on human information processing. In R. W. Proctor \& T. G. Reeve (Eds.) Stimulus-response compatibility: An integrated perspective (pp. 3186). Amsterdam: North-Holland.

Simon, J. R., Craft, J. L., \& Webster, J. B. (1973). Reactions toward the stimulus source: Analysis of correct responses and errors over a five-day period. Journal of Experimental Psychology, 101, 175-178.

Stoffels, E. J., van der Molen, M. W., \& Keuss, P. J. G. (1989). An additive factors analysis of the effects of location cues associated with auditory stimuli on stages of information processing. Acta Psychologica, 70, 161-197.

STROOP, J. R. (1992). Studies of interference in serial verbal reactions. Journal of Experimental Psychology: General, 121, 15-23. (Original work published 1935 in Journal of Experimental Psychology, 18, 643-662)

TeICHNer, W. H., \& KreBs, M. J. (1974). Laws of visual choice reaction time. Psychological Review, 81, 75-98.

Umiltà, C., \& NiCOLETTI, R. (1990). Spatial stimulus-response compatibility. In R. W. Proctor \& T. G. Reeve (Eds.), Stimulus-response compatibility: An integrated perspective (pp. 89-116). Amsterdam: North-Holland.

UMILTÀ, C., \& ZORZI, M. (1997). Commentary on Barber and O'Leary: Learning and attention in S-R compatibility. In B. Hommel \& W. Prinz (Eds.), Theoretical issues in stimulus-response compatibility (pp. 173178). Amsterdam: North-Holland.

WANG, H., \& Proctor, R. W. (1996). Stimulus-response compatibility as a function of stimulus code and response modality. Journal of Experimental Psychology: Human Perception \& Performance, 22, 1201-1217.

Welford, A. T. (1976). Skilled performance: Perceptual and motor skills. Glenview, IL: Scott, Foresman.

ZORZI, M., \& UMILTÀ, C. (1995). A computational model of the Simon effect. Psychological Research, 58, 193-205.

\section{NOTE}

1. At first glance, one might think that the reversed Simon effect found in the Hedge and Marsh (1975) task when the relevant S-R mapping is incompatible rules out an account of the Simon effect in terms of permanent associations between the corresponding stimulus and response locations. However, the reversal is usually attributed to misapplication of the opposite translation rule to the irrelevant stimulus location dimension (i.e., to the explicit S-R translation route of Figure 1). As is discussed in the introduction to Experiment 4, this rule-based activation of the opposite-location response may overshadow activation of the corresponding response location that occurs as well, by way of the automatic activation route illustrated in Figure 1 (see, e.g., De Jong et al., 1994)

(Manuscript received March 7. 1997; revision accepted for publication September 12, 1997.) 